\title{
The economic burden of traumatic spinal cord injury in Canada
}

\author{
H. Krueger, PhD (1, 2); V. K. Noonan, PhD, PT (1, 3); L. M. Trenaman, BSc (2); P. Joshi, PhD (3); C. S. Rivers, PhD (3)
}

This article has been peer reviewed.

\begin{abstract}
Introduction: The purpose of this study is to estimate the current lifetime economic burden of traumatic spinal cord injury (tSCI) in Canada from a societal perspective, including both direct and indirect costs, using an incidence-based approach.
\end{abstract}

Methods: Available resource use and cost information for complete/incomplete tetraplegia and paraplegia was applied to the estimated annual incidence of tSCI, by severity, in Canada.

Results: The estimated lifetime economic burden per individual with tSCI ranges from $\$ 1.5$ million for incomplete paraplegia to $\$ 3.0$ million for complete tetraplegia. The annual economic burden associated with 1389 new persons with tSCI surviving their initial hospitalization is estimated at $\$ 2.67$ billion.

Conclusion: While the number of injuries per year in Canada is relatively small, the annual economic burden is substantial.

Keywords: traumatic spinal cord injury, economic burden, morbidity, mortality

\section{Introduction}

Traumatic spinal cord injuries (tSCI) exact an extensive burden on the injured individual, their family and carers, and society as a whole. In addition to the physical and psychosocial trauma, the economic burden is thought to be substantial, due to increased health care costs as well as higher rates of morbidity and premature mortality. Information on the lifetime economic burden following a tSCI, however, is limited, especially in Canada.

Existing literature on the costs of tSCI tends to focus on subgroups of tSCI patients (e.g. veterans, ${ }^{1,2}$ those admitted to the United States Spinal Cord Injuries Model Systems hospitals, ${ }^{3,4,5}$ and workrelated injuries $\left.{ }^{6}\right)$, a particular aspect of the economic burden (e.g. rehabilitation and unplanned hospitalizations ${ }^{7,8}$ ) or a specific time frame following the tSCI. ${ }^{9}$
Two research groups, one in Canada ${ }^{9,10,11}$ and the other in the United States, ${ }^{12,13}$ have taken a population-based approach. The study from Alberta collected direct cost information for the first six years following a tSCI; ${ }^{9,10,11}$ the U.S. study considered lifetime direct and indirect costs, but these are from 1988 and need to be updated. Direct costs tend to include injury-related expenditures by the health care system and by the patient and/or the caregiver(s). ${ }^{12,13}$ Indirect costs "refer to the value of potential output that is lost as a result of any reduction or elimination of work or other activity due to SCI. These costs are measured as the losses that occur due to the reduction in productivity that results from morbidity or mortality attributable to SCI." 12, p12

Both the Alberta and the U.S. studies found that a population-based approach yielded a significantly different mix of patients when compared with an institution-based approach. ${ }^{10,12}$ That is, individuals with tSCI cared for by the U.S. Model System, for example, tend to have, on average, much more severe injuries compared with the general population of patients with tSCI. ${ }^{12}$ This difference can have an important effect on estimating the economic burden of tSCI.

Further, as most of the existing literature is from the U.S. and differences between the U.S. and Canadian health care systems make comparison difficult, there is a need for research on costs from a Canadian perspective.

This study uses the best information available in the literature to model the current lifetime economic burden of tSCI in Canada based on a societal perspective.

\section{Methods}

We used data from a variety of published sources to develop a model of the lifetime economic burden of tSCI by injury severity. Whenever possible, we used data from Canadian population-based studies. ${ }^{9,10,11}$ These were largely supplemented by data from the two U.S. populationbased studies, one published in $1992^{12,13}$ and the other in $1998^{14}$ (see Table 1). Costs based on the Canadian study were adjusted to 2011 dollars based on the Health and Personal Care (HPC) component of the Canadian Consumer Price Index (CPI). ${ }^{15}$ U.S. costs were adjusted to 2011 Canadian dollars by first converting them into equivalent Canadian dollars for the given year and then increasing them to 2011 Canadian dollars as above. 
TABLE 1

Base model assumptions

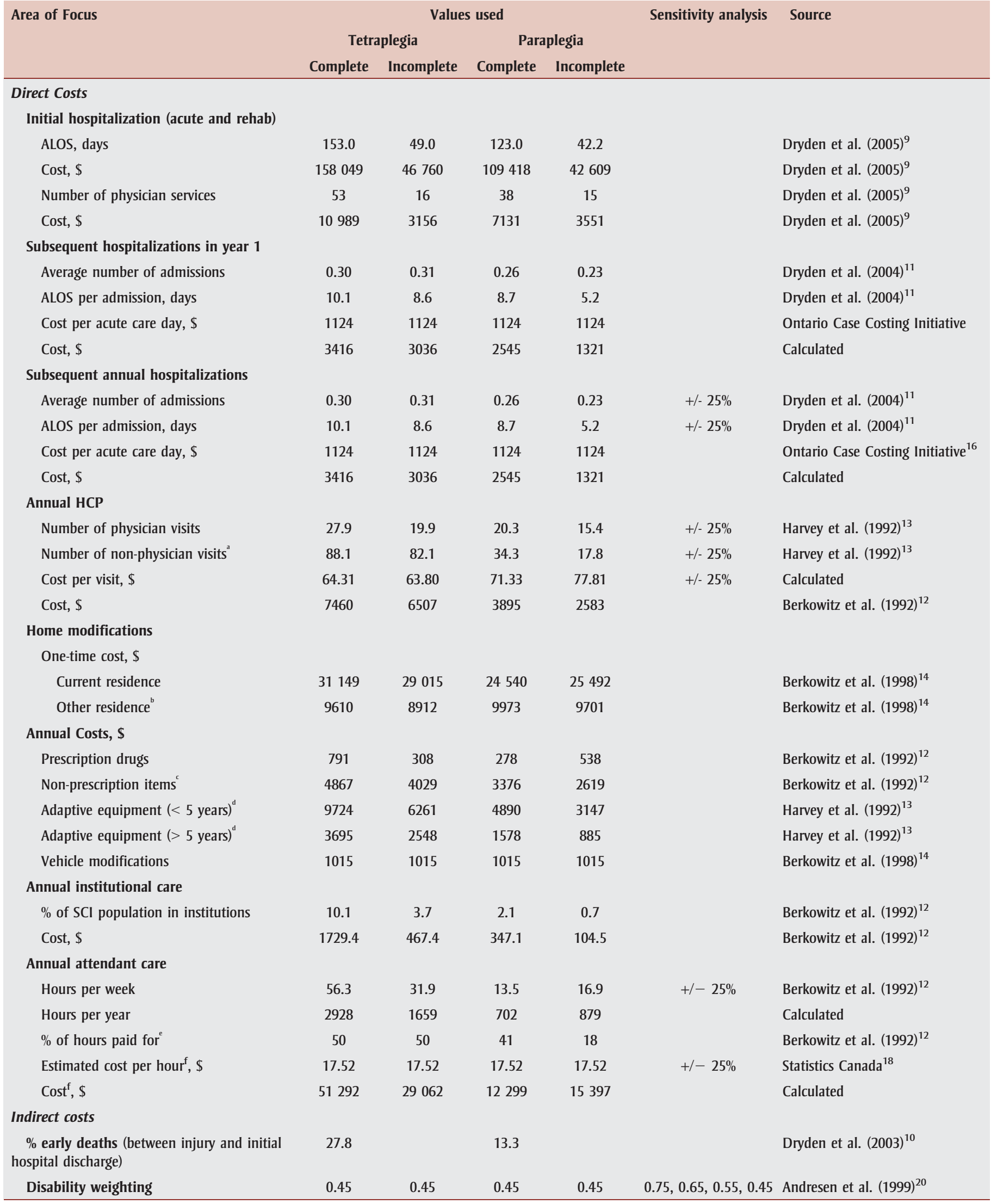


TABLE 1 (continued)

Base model assumptions

\begin{tabular}{|c|c|c|c|c|c|c|}
\hline \multirow[t]{3}{*}{ Area of Focus } & \multicolumn{4}{|c|}{ Values used } & \multirow[t]{3}{*}{ Sensitivity analysis } & \multirow[t]{3}{*}{ Source } \\
\hline & \multicolumn{2}{|c|}{ Tetraplegia } & \multicolumn{2}{|c|}{ Paraplegia } & & \\
\hline & Complete & Incomplete & Complete & Incomplete & & \\
\hline Life years lost (35-year-old SCI survivor) & 19.05 & 5.70 & 12.50 & 5.70 & $\begin{array}{l}25-45 \text { year old } \mathrm{SCI} \\
\text { survivor }\end{array}$ & $\begin{array}{l}\text { NSCISC Annual Statistical Report, } \\
2009^{21}\end{array}$ \\
\hline Value of a saved life year ${ }^{g}, \$$ & 47834 & 47834 & 47834 & 47834 & & $\begin{array}{l}\text { Statistics Canada Survey of Labour, } \\
\text { Income \& Dynamics }{ }^{19}\end{array}$ \\
\hline$\%$ of surviving SCI population & 7.7 & 46.8 & 11.7 & 33.8 & & Dryden et al. $(2005)^{9}$ \\
\hline Discount rate & 2.0 & 2.0 & 2.0 & 2.0 & $0 \%-4.0 \%$ & \\
\hline
\end{tabular}

Abbreviations: ALOS, average length of stay; CPI, Consumer Price index; HPC, health and personal care; HCP, health care practitioner; SCI, spinal cord injury.

a Physiotherapists, occupational therapists, psychologists, nurses, chiropractors, etc.

b Includes other homes owned by the SCI survivor as well as modifications to homes of family and friends specifically to accommodate the person with SCI.

c Includes non-prescription pain medication, catheters, dressings and bandages, laxatives, vitamins, rubber gloves, etc. ${ }^{12}$

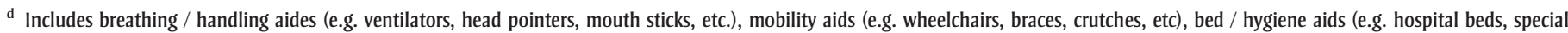
mattresses, bed or bath lifts, commode seats, etc.) and exercise and other miscellaneous items (e.g. exercise bikes, weights, special telephones, etc.)

e A proportion of the hours worked for which the person providing the service received remuneration.

f Based on the median Canadian hourly wage for "Assisting Occupations in Support of Health Services", 2005 value of \$15.669 adjusted to 2011 using the HPC component of the CPI $(+11.8 \%)^{18}$

${ }^{8}$ Based on the median Canadian earnings of full-year full-time workers, 2009 value of $\$ 45,600$ (Survey of Labour, Income and Dynamics) adjusted to 2011 using the CPI (+4.9\%). ${ }^{19}$

\section{Direct costs}

We derived costs associated with initial hospitalization from the work by Dryden et al. ${ }^{9}$ in Alberta.

We calculated the cost per acute care day for hospitalizations following the initial hospitalization based on costs from the Ontario Case Costing Initiative ${ }^{16}$ using a mix of in-patient admissions for diseases of the genitourinary system (47\%), skin and subcutaneous tissue (35\%) and the respiratory system $(18 \%) .{ }^{17}$ This approach was used because the majority of hospitalizations after an initial injury are for these three complications. We then applied the cost per acute care developed in this fashion in valuing all acute hospitalizations, including those for depression, substance abuse, etc.

Visits to non-physicians included services provided by physiotherapists, occupational therapists, psychologists, nurses, chiropractors, etc. ${ }^{13}$ Home modifications included all those designed specifically to accommodate the person with SCI in both the principal and any secondary homes, in addition to the homes of family and friends. ${ }^{14}$ Non-prescription items included non-prescription pain medication, cathe- ters, dressings and bandages, laxatives, vitamins and rubber gloves. ${ }^{12}$ Adaptive equipment includes breathing/handling aides (e.g. ventilators), mobility aids (e.g. wheelchairs, braces, crutches), bed/ hygiene aids (e.g. hospital beds, special mattresses, bed or bath lifts, commode seats) and exercise and other miscellaneous items (e.g. exercise bikes, weights, special telephones). ${ }^{13}$

The cost per hour for attendant care was based on the median Canadian hourly wage for "Assisting Occupations in Support of Health Services.”,18

\section{Indirect costs}

We used a modified human-capital approach (in which unpaid time is explicitly valued) to calculate indirect costs; in this way, a quality-adjusted life year (QALY) was valued at \$47 834 (the average Canadian annual wage rate in $2011)^{19}$ regardless of the individual's age or work status. Life years lost were quality-adjusted based on a utility of 0.45 , which has been reported for persons with SCI. ${ }^{20}$ Thus, one year of life with an SCI would receive a value of 0.45 QALYs. The loss of 0.55 QALYs was thus valued at $\$ 26309(0.55 \times \$ 47834)$. In this way, indirect costs would accumulate postinjury for persons living with SCI.

Life years lost associated with an SCI were based on the age and life expectancy based on injury severity derived from the 2009 National Spinal Cord Injury Statistical Center (NSCISC) Annual Statistical Report $^{21}$ and adjusted for differences in the life expectancy of the Canadian population. ${ }^{22}$ That is, individuals with an SCI die sooner than if they did not have that injury, with the number of life years lost increasing with the severity of the injury. Each of these life years lost were assigned a value of $\$ 47834$

The economic burden of tSCI in Canada was developed using an incidence-based approach. "An incidence-based approach measures the (lifetime) costs associated with all new injuries occurring within a given period (usually a year), while a prevalence-based approach measures costs incurred by all SCI individuals alive in a given period." ${ }^{2, p 14}$ We took the annual incidence of tSCI surviving hospitalization in Canada (1389) from Noonan et al., ${ }^{23}$ and derived the distribution of injury severity (106 [7.7\%] with complete tetraplegia, 651 [46.8\%] with incomplete tetraplegia, 163 [11.7\%] with complete 
paraplegia and 469 [33.8\%] with incomplete paraplegia) from Dryden et al. ${ }^{10}$

All costs were discounted at an annual rate of $2 \%$. The discount rate "is the rate at which we devalue the costs incurring into the future." 12, p168 This rate was varied from $0 \%$ to $4 \%$ in the sensitivity analysis.

Sensitivity analysis is frequently used in economic studies to vary key assumptions and determine if these changes have an important effect on the overall results. In this study, we applied sensitivity analyses to the major cost drivers including age at injury, disability weighting, discount rate, hospital admissions, health care practitioner (HCP) visits and attendant care (see Table 1).

\section{Results}

The estimated lifetime economic burden associated with a tSCI in Canada ranges from $\$ 1.47$ million for a person with incomplete paraplegia to $\$ 3.03$ million for one with complete tetraplegia (see Table 2). Of the total costs, direct costs represent between $44 \%$ and $51 \%$ in patients with paraplegia and between and $56 \%$ and $66 \%$ in patients with tetraplegia. Within direct costs, the most significant cost driver was the cost of attendant care following the injury. These costs alone ranged from $\$ 0.29$ million to $\$ 1.02$ million (38\%-60\% of direct costs). Hospitalization costs ranged from $\$ 0.08$ million to $\$ 0.23$ million $(5 \%-13 \%$ of direct costs) while HCP costs ranged from
$\$ 0.07$ million to $\$ 0.15$ million $(10 \%-13 \%$ of direct costs).

The estimated annual economic burden associated with tSCI in Canada is \$2.67 billion ( $\$ 1.57$ billion in direct costs and $\$ 1.10$ billion in indirect costs; see Table 3). Costs associated with hospitalizations ( $\$ 0.17$ billion or $6.5 \%$ of total costs), HCP visits ( $\$ 0.18$ billion or $6.7 \%$ ), equipment and home modifications ( $\$ 0.31$ billion or $11.6 \%$ ) and attendant care ( $\$ 0.87$ billion or $32.7 \%$ ) are the major direct cost drivers.

The results of the sensitivity analyses are summarized in Table 4. Costs are most sensitive to the choice of discount rate. Excluding any discounting (an effective

TABLE 2

Lifetime economic burden associated with spinal cord injury

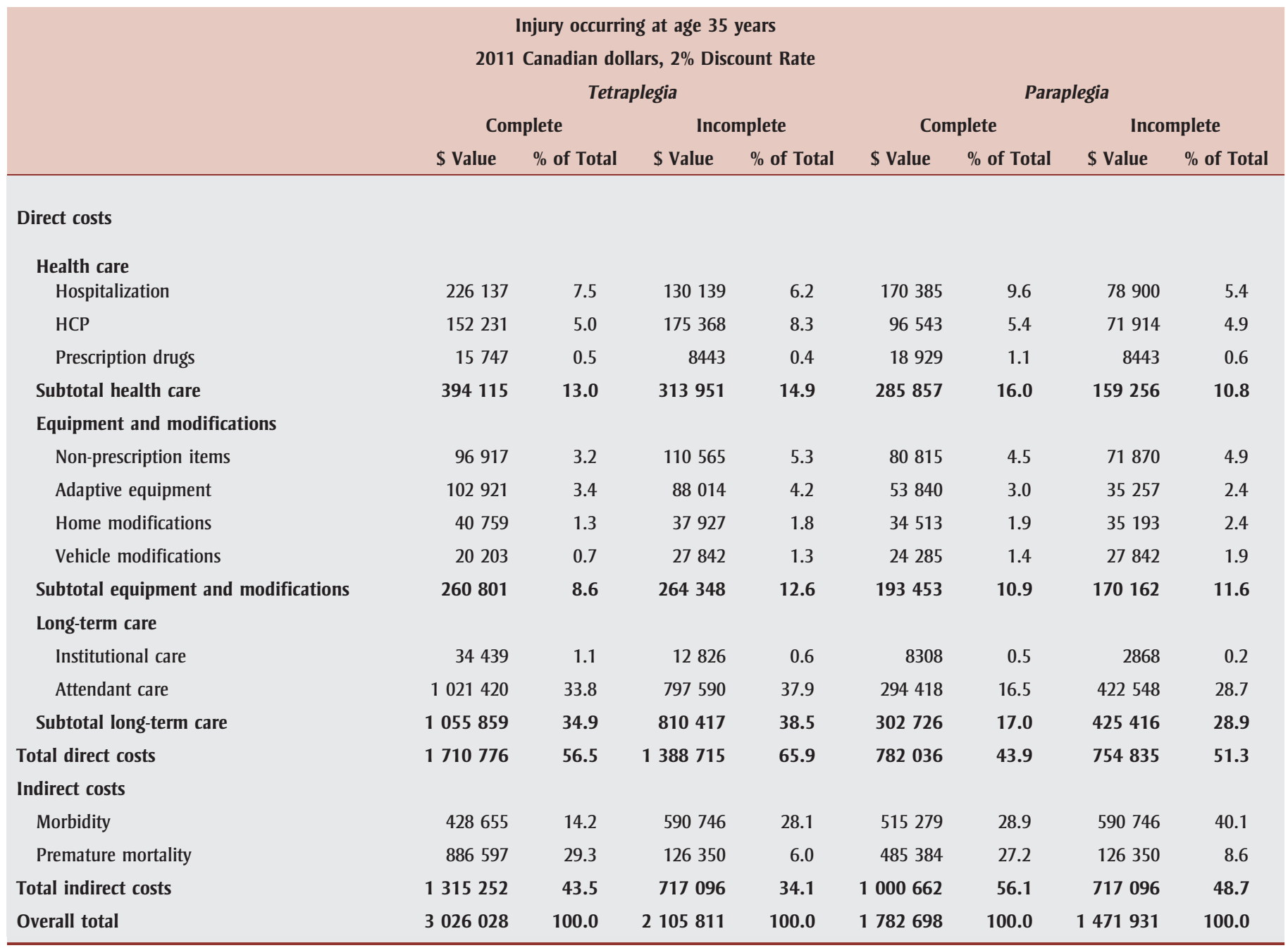

Abbreviation: HCP, health care practitioner. 
TABLE 3

Annual economic burden associated with spinal cord injury in Canada

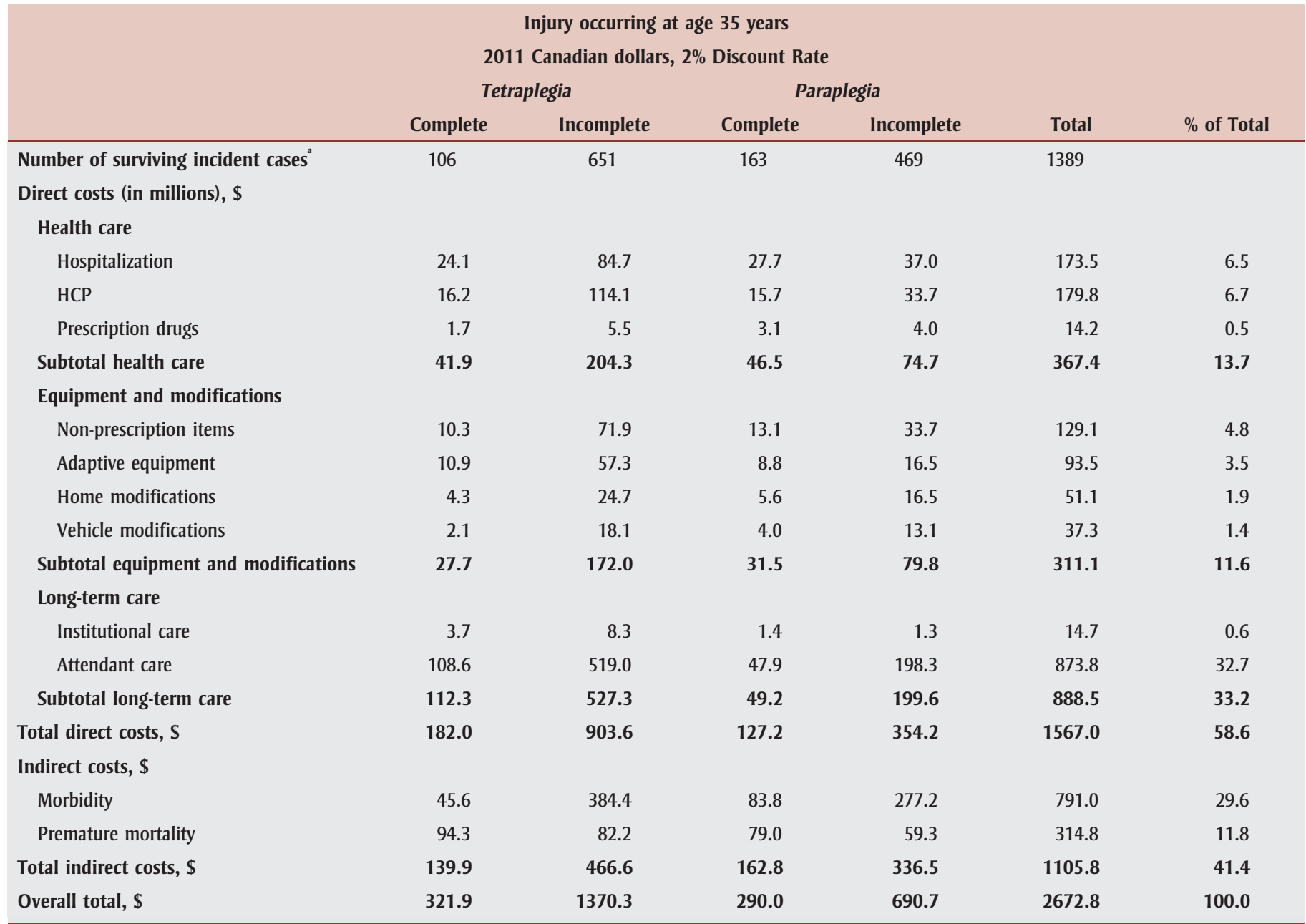

Abbreviation: HCP, health care provider.

a 1389 patients per year survive to be discharged following their initial hospitalization. ${ }^{23}$

rate of $0 \%$ ) increases the lifetime economic burden by $38 \%$ to $47 \%$. Using a discount rate of $4 \%$ (compared to the base case discount rate of $2 \%$ ) decreases the lifetime economic burden by $23 \%$ to $27 \%$. The age at which the injury is sustained also has a significant effect. Using an average age of 25 years (compared to the base case assumption of 35 years) increases overall costs by $10 \%$ to $14 \%$ while using age 45 years decreases overall costs by $14 \%$ to $18 \%$. Varying the disability weighting from 0.45 for all injuries to $0.45,0.55,0.65$ and 0.75 for incomplete paraplegia, incomplete tetraplegia, complete paraplegia and complete tetraplegia, respectively, increases indirect costs by $18 \%$ to $23 \%$.

Direct care costs are most sensitive to assumptions regarding the hours of atten- dant care received. Increasing the annual number of hours of care received per year or the average wage rate by $25 \%$ increases direct costs by $9 \%$ to $15 \%$. If both the number of hours and the wage rate are increased by $25 \%$, then direct costs would increase by $21 \%$ to $34 \%$.

\section{Discussion}

To our knowledge, this is the first attempt to quantify the lifetime economic burden of tSCI in Canada. We have attempted to be as extensive as possible in the scope of the costs included.

The value of cost-of-illness studies has been questioned, particularly given the varied approaches and methodological limitations associated with this type of research. $^{24,25,26}$ However, Segui-Gomez and Mackenzie $^{27}$ note that a variety of metrics, including economic burden, are important when assessing the impact to society of injuries, particularly non-fatal injuries. Rice ${ }^{28}$ notes that cost-of-illness studies "translate the adverse effects of diseases and injuries into dollar terms, the universal language of decision makers and the policy arena. These estimates are used to: (1) define the magnitude of the disease or injury in dollar terms; (2) justify intervention programs; (3) assist in the allocation of research dollars on specific diseases; (4) provide a basis for policy and planning relative to prevention and control initiatives; and (5) provide an economic framework for program evaluation.,"28,p178

Unfortunately, the application of these studies to the policy arena continues to be problematic. For example, in 1995 the 
TABLE 4

Lifetime economic burden associated with spinal cord injury

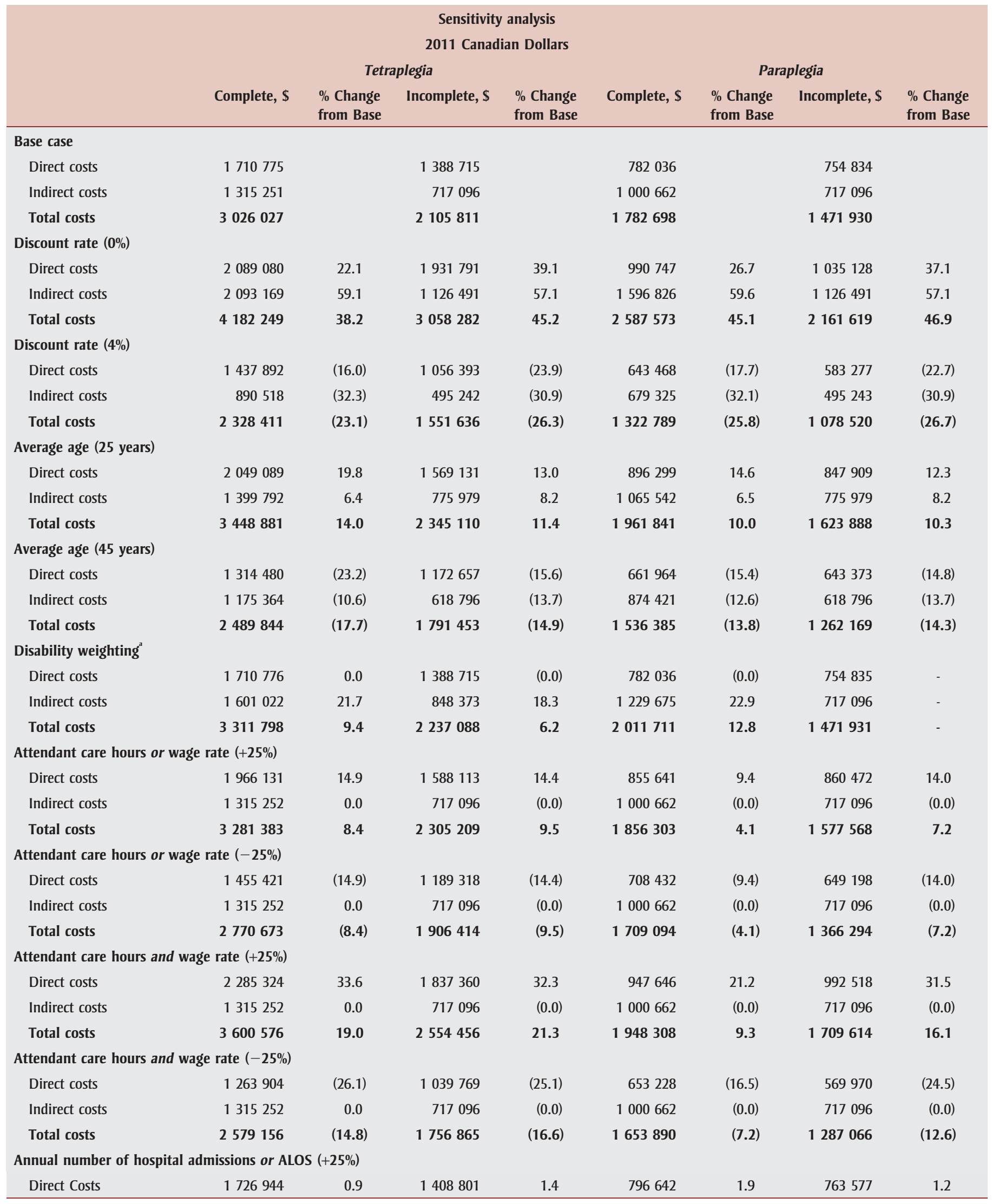


TABLE 4 (continued)

Lifetime economic burden associated with spinal cord injury

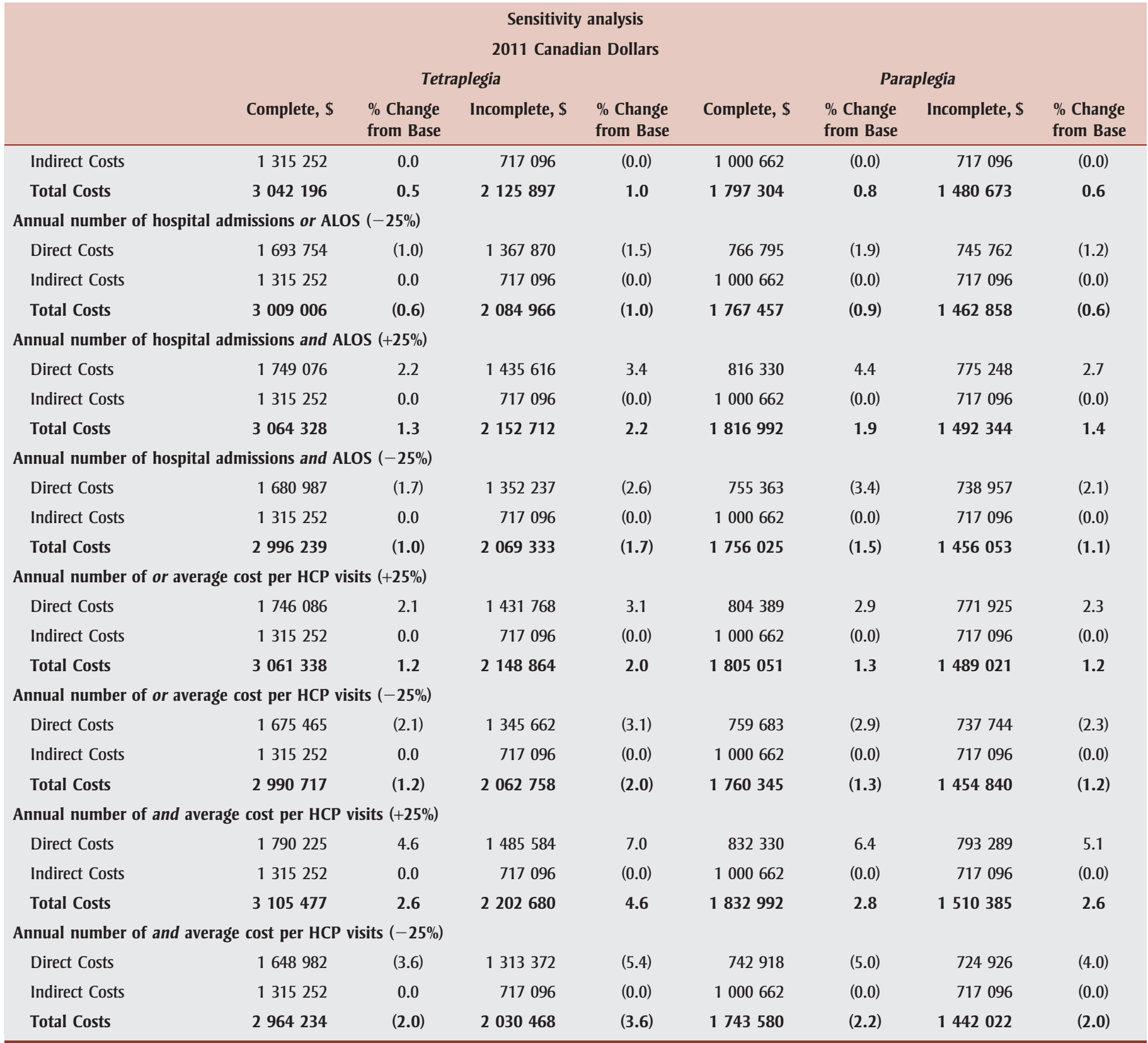

Abbreviations: ALOS, average length of stay; HCP, health care practitioner.

${ }^{\mathrm{a}}$ Complete tetraplegia $=0.75$; complete paraplegia $=0.65$; incomplete tetraplegia $=0.55$; incomplete paraplagia $=0.45$.

U.S. Senate Committee on Appropriations recommended that the National Institutes of Health $(\mathrm{NIH})$ produce a report on the societal cost of the diseases for which the $\mathrm{NIH}$ conducts and funds research. ${ }^{28} \mathrm{~A}$ 1998 review by the U.S. Institute of Medicine recommended that the NIH strengthen its use of data on "disease burden and costs" in setting research funding priorities. ${ }^{29}$ Despite producing disease-specific cost-of-illness reports in
1995, 1997 and 2000, ${ }^{28}$ this information does not appear to be used in current research funding allocations by the NIH. ${ }^{30,31}$

In an attempt to reduce the methodological heterogeneity of cost-of-illness studies while recognizing the "strong continuing demand for economic impact studies, ,32,p2 associations such as the World Health Organization have proposed a framework for conducting cost-of-illness studies "with a view to enhancing the consistency and coherence of economic impact studies in health.",32,p3

There are important limitations associated with this analysis. The analysis depends on published data from a variety of sources and timeframes rather than detailed costing of a patient cohort. Average costs also mask the wide varia- 
tion in individual costs, even when accounting for the severity of the injury. As a result, these costs should not replace any professionally developed life care plan and the costs of implementing that care. In addition, no attempt was made to determine whether these costs are associated with optimal or even adequate care. In the U.S., Webster et al. ${ }^{6}$ found that "those with work-related tetraplegia may receive more injury-related paid medical benefits after the first year post-injury than cases who do not receive (workers compensation)-supported benefits."6,p240

Estimating acute care costs is based on an aggregated disease-specific cost per patient day. An alternative approach would be to use Resource Intensity Weights assigned to each hospitalization together with an estimated cost per Resource Intensity Weight. The required information on specific hospitalizations, however, is currently unavailable but is something that the Rick Hansen Institute is in the process of addressing.

While an incidence-based approach to costing is nominally based on a trajectory of estimated life-time costs, in reality it requires an assumption (for this study) of functional status at a point in time. Actual changes in costs associated with changing functional status would only be possible given longterm, individual patient-level data.

The most commonly used method in valuing indirect costs is the human-capital approach. In this approach, gender- and age-specific average earnings are combined with productivity trends and years of life lost due to a specific disease/ condition to estimate unrealized lifetime earnings. An important criticism of this method is that it places a higher value on the years of life lost for someone with higher earning potential (e.g. men aged 35-55 years) than someone with lower earning potential (e.g. women aged 75+ years). ${ }^{33}$ In particular, unpaid work and leisure time are not explicitly accounted for in the human-capital approach. ${ }^{34}$

In calculating indirect costs, we used a modified human-capital approach in which unpaid time is explicitly valued. This approach involved assigning a value of $\$ 47834$ (the average annual Canadian wage rate in 2011) to every QALY lost. The inclusion of valuing unpaid time within the human capital approach has been suggested by a number of researchers $^{35,36}$ to address the inherent bias of the approach in undervaluing the impact of illness or injury in retired elderly people, the disabled and those who choose not to be gainfully employed.

Cao et al. ${ }^{4}$ recently estimated the value of average lifetime direct costs (versus charges) in the U.S. for an injury sustained at age 25 years and using a $2 \%$ discount rate. The range was from $\$ 1.10$ million (in 2009 U.S. dollars) for an American Spinal Injury Association (ASIA) Impairment Scale (AIS) D injury at any level to $\$ 3.41$ million for a C1-4 AIS A, B or C injury. Using the same major assumptions (injury at age 25 years, $2 \%$ discount rate), the present value of average lifetime direct costs derived from our analysis ranges from $\$ 0.85$ million to $\$ 2.05$ million, or approximately $23 \%$ to $40 \%$ lower than the U.S. estimate.

One possible reason for this difference is the higher overall cost of providing health care in the U.S. due to a combination of higher prices, administrative overhead costs, use of high-cost equipment and the practice of "defensive medicine" triggered by uniquely American tort laws. Excess costs in the U.S. are estimated to be approximately $40 \%$ over that of international comparators. ${ }^{38}$

A further possibility for the disparity is the way in which attendant care is determined. DeVivo et al. $^{5}$ estimated the annual hours of attendant care beginning in the second year following the injury to be from 1124 for an AIS D injury at any level to 5453 for a C1-4 A, B or C injury. ${ }^{5}$ Each paid or unpaid hour was valued at $\$ 21.00$ (in 2009 U.S. dollars). The annual number of hours appears to be derived "based on self-report of all persons in the NSCISC database who completed an annual follow-up evaluation between 2000 and 2006 and had complete data on this item." ${ }^{, p 4}$ We used the considerably lower estimate (ranging from 702 to 2928 hours annually) from the Berkowitz et al. ${ }^{14}$ population-based study and applied a value of $\$ 17.52$ per hour for both paid and unpaid hours. Comprehensive estimates of attendant care costs in the Canadian SCI population are needed, particularly because these costs are the single largest driver of direct costs.

Finally, it is important to note the difference when institution-based prevalence rather than population-based prevalence is used. In both the Canadian and U.S. population-based studies, the proportion of the SCI population with complete tetraplegia or paraplegia is similar, at $7 \%$ to $8 \%$ and $10 \%$ to $12 \%$, respectively, whereas the prevalence of complete tetraplegia or paraplegia based on persons with SCI receiving care in the U.S. Model System tends to be substantially higher at $24 \%$ and $27 \%$, respectively. ${ }^{10,12}$ This overweighting of more severe injuries is important to take into account, particularly when estimating the annual economic burden associated with tSCI.

To our knowledge, this is the first attempt to estimate the economic burden of $\mathrm{TSCI}$ in Canada. While the number of injuries per year is relatively small, the annual economic burden, at $\$ 2.67$ billion, is substantial. This burden could be reduced if some of the new cases could be avoided or if function could be improved ${ }^{39}$ or secondary complications prevented (either through functional improvements or better management) after the tSCI occurs.

\section{Acknowledgements}

This study was funded by the Rick Hansen Institute and Health Canada.

Hans Krueger and Logan Trenaman received funding from the Rick Hansen Institute for this work. Vanessa Noonan, Phalgun Joshi, and Carly Rivers are employees of the Rick Hansen Institute.

\section{References}

1. French DD, Campbell RR, Sabharwal S, Nelson AL, Palacios PA, Gavin-Dreschnack D. Health care costs for patients with chronic spinal cord injury in the Veterans Health Administration. J Spinal Cord Med. 2007;30(5):477. 
2. St Andre JR, Smith BM, Stroupe KT, Burns SP, Evans CT, Ripley DC, et al. A comparison of costs and health care utilization for veterans with traumatic and nontraumatic spinal cord injury. Top Spinal Cord Inj Rehabil. 2011;16(4):27-42.

3. DeVivo MJ. Causes and costs of spinal cord injury in the United States. Spinal Cord. 1997;35(12):809-13.

4. Cao Y, Chen Y, DeVivo M. Lifetime direct costs after spinal cord injury. Top Spinal Cord Inj Rehabil. 2011;16(4):10-6.

5. DeVivo M, Chen $\mathrm{Y}$, Mennemeyer ST, Deutsch A. Cost of care following spinal cord injury. Top Spinal Cord Inj Rehabil. 2011;16(4):1-9.

6. Webster B, Giunti G, Young A, Pransky G, Nesathurai S. Work-related tetraplegia: cause of injury and annual medical costs. Spinal Cord. 2004;42(4):240-7. p240.

7. Kiekens C, Van Rie K, Peers K, Lysens R. Cost of rehabilitation care in traumatic and nontraumatic spinal cord injury in a European context. Top Spinal Cord Inj Rehabil. 2011;16(4):43-52.

8. DeVivo M, Farris V. Causes and costs of unplanned hospitalizations among persons with spinal cord injury. Top Spinal Cord Inj Rehabil. 2011;16(4):53-61.

9. Dryden DM, Saunders LD, Jacobs P, et al. Direct health care costs after traumatic spinal cord injury. J Trauma. 2005;59(2): 443-9.

10. Dryden DM, Saunders LD, Rowe BH, et al. The epidemiology of traumatic spinal cord injury in Alberta, Canada. Can J Neurol Sci. 2003;30(2):113-21.

11. Dryden DM, Saunders LD, Rowe BH, et al. Utilization of health services following spinal cord injury: a 6-year follow-up study. Spinal Cord. 2004;42(9):513-25.

12. Berkowitz M, Harvey C, Greene CG, Wilson $\mathrm{SE}$. The economic consequences of traumatic spinal cord injury. New York: Demos Medical Publishing; 1992.

13. Harvey C, Wilson SE, Greene CG, Berkowitz M, Stripling TE. New estimates of the direct costs of traumatic spinal cord injuries: results of a nationwide survey. Paraplegia. 1992;30(12):834-50.
14. Berkowitz M, O’Leary PK, Kruse DL, Harvey C. Spinal cord injury: an analysis of medical and social costs. New York: Demos Medical Publishing; 1998.

15. Statistics Canada. Consumer price index (CPI) [Internet]. Ottawa (ON): Statistics Canada; 2010 [cited 2011 Nov 15]. Available from: http://www.statcan.gc.ca /cgi-bin/imdb/p2SV.pl?Function = getSurvey\& SDDS $=2301 \&$ lang $=$ en $\& \mathrm{db}=\mathrm{imdb} \& \mathrm{adm}=8 \&$ dis $=2$

16. Ontario Case Costing Initiative. Costing analysis tool [Internet]. Toronto (ON): Ontario Case Costing Initiative; 2011 [cited 2011 Nov 15]. Available from: www.occp .com/mainPage.htm

17. Cardenas DD, Hoffman JM, Kirshblum S, McKinley W. Etiology and incidence of rehospitalization after traumatic spinal cord injury: a multicenter analysis. Arch Phys Med Rehabil. 2004;85(11):1757-63.

18. Statistics Canada. Median earnings and employment for full-year, full-time earners, all occupations, both sexes, for Canada, provinces and territories - $20 \%$ sample data [Internet]. Ottawa (ON): Statistics Canada; 2010 [cited 2011 Nov 15]. Available from: http://www12.statcan.gc.ca /census-recensement/2006/dp-pd/hlt/97-563 /T801-eng.cfm? Lang $=\mathrm{E} \& \mathrm{~T}=801 \& \mathrm{GH}=4 \& \mathrm{SC}$ $=1 \& \mathrm{SO}=99 \& \mathrm{O}=\mathrm{A}$

19. Statistics Canada. Income in Canada [Internet]. Ottawa(ON): Statistics Canada; 2011 [cited 2011 Nov 25]. Available from: http://www.statcan.gc.ca/pub/75-202-x /75-202-x2009000-eng.htm

20. Andresen EM, Fouts BS, Romeis JC, Brownson CA. Performance of healthrelated quality-of-life instruments in a spinal cord injured population. Arch Phys Med Rehabil. 1999;80(8):877-84.

21. National Spinal Cord Injury Statistical Center (NSCISC). NSCISC annual statistical report [Internet]. Birmingham (AL): NSCISC; 2009 [cited 2011 Nov 15]. Available from: https: //www.nscisc.uab.edu/PublicDocuments /reports/pdf/2009\%20NSCISC\%20Annual\% 20Statistical\%20Report \%20-\%20Complete\% 20Public\%20Version.pdf
22. Statistics Canada. Life tables, Canada, provinces and territories [Internet]. Ottawa (ON): Statistics Canada; 2006 [cited 2011 Nov 15]. Available from: http://www5.statcan.gc.ca /bsolc/olc-cel/olc-cel?catno $=84-537$-XIE\&lang = eng

23. Noonan VK, Fingas M, Farry A, et al. Incidence and prevalence of spinal cord injury in Canada: a national perspective. Neuroepidemiology. 2012;38(4):219-26.

24. Currie G, Kerfoot KD, Donaldson C, Macarthur C. Are cost of injury studies useful? Inj Prev. 2000 Sep;6(3):175-6.

25. Bloom BS, Bruno DJ, Maman DY, Jayadevappa R. Usefulness of US cost-ofillness studies in healthcare decision making. Pharmacoeconomics. 2001;19(2):207-13.

26. Clabaugh G, Ward MM. Cost-of-illness studies in the United States: a systematic review of methodologies used for direct cost. Value Health. 2008 Jan-Feb;11(1):13-21.

27. Segui-Gomez M, MacKenzie EJ. Measuring the public health impact of injuries. Epidemiol Rev. 2003;25:3-19.

28. Rice DP. Cost of illness studies: what is good about them? Inj Prev. 2000 Sep;6(3):177-9.

29. Institute of Medicine (US) Committee on the NIH Research Priority-Setting Process. Scientific opportunities and public needs: improving priority setting and public input at the National Institutes of Health. Washington (DC): National Academies Press; 1998.

30. Gross CP, Anderson GF, Powe NR. The relation between funding by the National Institutes of Health and the burden of disease. N Engl J Med. 1999 Jun $17 ; 340(24): 1881-7$

31. Gillum LA, Gouveia C, Dorsey ER, et al. NIH disease funding levels and burden of disease. PLoS One. 2011 Feb 24;6(2):e16837.

32. World Health Organization, Department of Health Systems. WHO guide to identifying the economic consequences of disease and injury. Geneva (CH): World Health Organization; 2009. p2, p3. 
33. Yabroff KR, Bradley $\mathrm{CJ}$, Mariotto $\mathrm{AB}$, Brown ML, Feuer EJ. Estimates and projections of value of life lost from cancer deaths in the United States. J Natl Cancer Inst. 2008 Dec 17;100(24):1755-62.

34. Tranmer JE, Guerriere DN, Ungar WJ, Coyte PC. Valuing patient and caregiver time: a review of the literature. Pharmacoeconomics. 2005;23(5):449-59.

35. Health Canada, Policy Research Division. Economic burden of illness in Canada, 1998 [Internet]. Ottawa (ON): Health Canada; 1998 [cited 2011 Nov 15]. Available at: http://www.phac-aspc.gc.ca /ebic-femc/ebic-femc98/pdf/ebic1998.pdf

36. Krueger H, Lindsay P, Cote R, Kapral MK, Kaczorowski J, Hill MD. Cost avoidance associated with optimal stroke care in Canada. Stroke. 2012 Aug;43(8):2198-206.

37. Reinhardt UE. Why does U.S. health care cost so much? (Part I) [Internet]. New York (NY): New York Times; 2008 [cited 2011 Nov 15]. Available from http://economix .blogs.nytimes.com/2008/11/14/why-does -us-health-care-cost-so-much-part-i/

38. Anderson GF, Reinhardt UE, Hussey PS, Petrosyan V. It's the prices, stupid: why the United States is so different from other countries. Health Aff. 2003;22(3):89-105.

39. Fehlings MG, Vaccaro A, Wilson JR, et al. Early versus delayed decompression for traumatic cervical spinal cord injury: results of the Surgical Timing in Acute Spinal Cord Injury Study (STASCIS). PloS One. 2012;7(2):e32037. 